Available online at GSC Online Press Directory

GSC Biological and Pharmaceutical Sciences

e-ISSN: 2581-3250, CODEN (USA): GBPSC2

Journal homepage: https://www.gsconlinepress.com/journals/gscbps

(REVIEW ARTICLE)

\title{
Review on phytosomes: A novel drug delivery system
}

\author{
Mahadev B. Khanzode * Archana D. Kajale, Madhuri A. Channawar and Shilpa R. Gawande \\ ${ }^{1}$ Department of pharmaceutical P. Wadhwani College of pharmacy Yavtmal (M.S) 445001, India.
}

Publication history: Received on 16 September 2020; revised on 22 October 2020; accepted on 24 October 2020

Article DOI: https://doi.org/10.30574/gscbps.2020.13.1.0345

\begin{abstract}
The term "Phyto" means plant and "some" means cell It is also mentioned as herbosomes this is a new patented technology, where standardized plant extracts or water soluble phytoconstituents are complexed with phospholipids to produce lipid compatible molecular complexes, there by greatly increasing absorption and bioavailability. The recent development and conducted works of various researchers have been studied thoroughly to establish the transdermal route as a potential way to deliver phytoconstituents. Plant derived products or plant extracts are increasingly receiving attention as dietary supplements for the homeostatic management of inflammation, toxicities, cancers, weight loss and other chronic or acute degenerative disorders. But these products frequently face stability and bioavailability problems. Plant products after their isolation become prone to instability and are potentially unfit to cross the bio membrane as such. The phytosome technique reduces these tasks to reasonable extents. The phytosome or Herbosome technique increases the hydrophilicity of highly lipophilic drug there by making it suitable for drug delivery and increases the lipophilicity of hydrophilic phytoconstituents adequately to cross biological membrane. The topical application of phytosomes for cosmetic purpose has already been proven. This review also contains a comparative account of liposomes and phytosomes along with recent advancements in the field of phytosome technology with a special concern to transdermal drug delivery. The poor oral bioavailability of polyphenolic compound can be enhanced through the incorporation of them into phospholipid based self-assembled delivery system, i.e. popularly known as phytosome. There are number of products available in the market that contains phytosomal drug delivery system such as Ginkgo biloba, Silybum marianum, and Camellia sinensis.
\end{abstract}

Keywords: Phytosome; Plant; Phospholipid; Herbosomes; Bioavability; Product; technology

\section{Introduction}

Most of the biologically active constituents of plants are polar or water soluble but due to the problem in absorption, restricts the utilization of these type of compounds which ultimately decreases the bioavailability.

For improvement of bioavailability, herbal products must have proper homeostasis between hydrophilic (for absorption into gastrointestinal tract fluid) and lipophilic (to cross lipid bio membrane balance) [1]. Plant preparations are widely used in traditional as well as modern medicine system. During the traditional time, various pharmacological studies have been carried out with many plants extracts and their constituents to check their therapeutic application. Over the past year, great advancement has been made for the development of novel drug delivery system (NDDS) for various plant extracts and their active constituents. Novel drug delivery such as targeted drug delivery which directly channels the active entity on the site of action and such delivery system could offer targeted and sustained release of drug so that pharmacological effect could be achieved at lower dose. The development in the area of herbal medicine started earlier to cure human diseases with lesser side effects [2].

\footnotetext{
${ }^{*}$ Corresponding author: Mahadev b. Khanzode

Department of pharmaceutical P. Wadhwani College of pharmacy Yavtmal (M.S) 445001, India.
}

Copyright (C) 2020 Author(s) retain the copyright of this article. This article is published under the terms of the Creative Commons Attribution Liscense 4.0. 
A number of chief constituents of herbal medicine are easily soluble in water (glycoside, flavonoid); however, these constituents are bounded in their potency because they may be partially soluble or hydrophobic in nature, so when applied topically shows less therapeutic efficacy. Numerous efforts have been put forward to enhance the bioavailability of such drug by formulating them to target drug delivery system such as phytosomes and liposomes are good options. The use of these techniques in formulation development process may lead to good bioavailability of herbal drugs as compare to conventional herbal extracts [3].

Phytosomes means herbal drug loaded in vesicles, which is available in the Nano form. The phytosome provide an envelope, like coating around the active constituent of drug and due to this the chief constituent of herbal extract remains safe from degradation by digestive secretion and bacteria. Phytosome is effectively able to absorb from a water loving environment into lipid loving environment of the cell membrane and finally reaching to blood circulation. The current review highlights the future scope and emerging technologies in the field of NDDS for the benefit of herbal and traditional medicines prepared from plant origins [4].

The term "Phyto" means plant and "some" means cell like- It is also mentioned as herbosomes. This is a new patented technology, where standardized plant extracts or water soluble phytoconstituents are complexed with phospholipids to produce lipid compatible molecular complexes, there by greatly increasing absorption and bioavailability. Phosphatidylcholine, phosphatidylserine, phosphatidylethanolamine, phosphatidylinositol are the phospholipids used, but phosphatidylcholine are widely used because of their certain therapeutic value in case of liver diseases, alcoholic steatosis, drug induced liver damage and hepatitis. Phospholipids are also employed as natural digestive aids and as carriers for both fat miscible and water miscible nutrients. Phytosomes can easily traverse the lipophilic path of the enterohepatic cell membranes and also stratum corneum layer of the skin [5].

Standardized plant extracts mainly flavonoids are derived as phytosomes. Selection of flavonoids are done from the groups consisting of quercetin, kaemferol, quercretin-3, rhamnoglucoside, quercetin-3-rhamnoside, hyperoxide, vitexin, diosmine, 3-rhamnoside, (+) catechin, (-) epicatechin, apigenin-7-glucoside, luteolin, luteolin glucoside, ginkgonetine, isoginkgonetine and bilobetine etc.

\section{Phytosome technology $\&$ its advantage}

The phytosome technology was developed by Indena s.p.A of Italy, markedly enhancing the bioavailability of selected phytomedicines, by incorporating phospholipids into standardized plant extract, which improve their absorption and utilization. The polyphenols are little soluble both in water and in lipids. The polar functionalities of the lipophilic guest interact via hydrogen bonds and polar interaction with the charged phosphate head of phospholipids, forming a unique arrangement that can be evidenced by spectroscopy ${ }^{8}$. As phosphatidylcholine is a bifunctional molecule with hydrophilic choline and hydrophobic phosphatidyl group (Figure.1), the choline group head binds with the compound, while phosphatidyl portion envelopes the bounded part (Figure.2).

The first phytosome generation was prepared by combining selected polyphenolic extract with phospholipids in nonpolar solvent, but recently the phytosome generations are developed by using hydro- ethanolic solvent, to comply with current food specifications.

As compared to conventional herbal formulation, phytosome have following advantage [6].

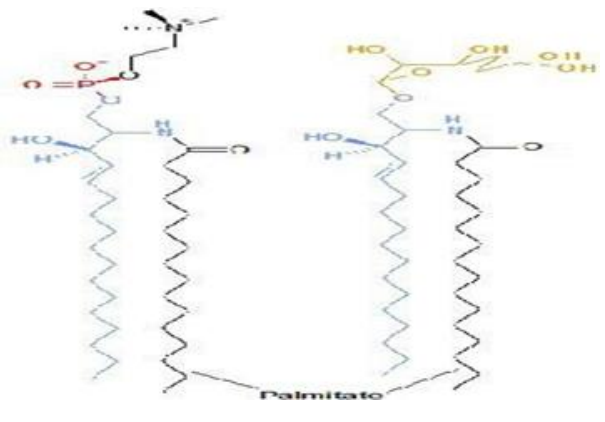

Figure1 Structure of Phosphatidylcholine 


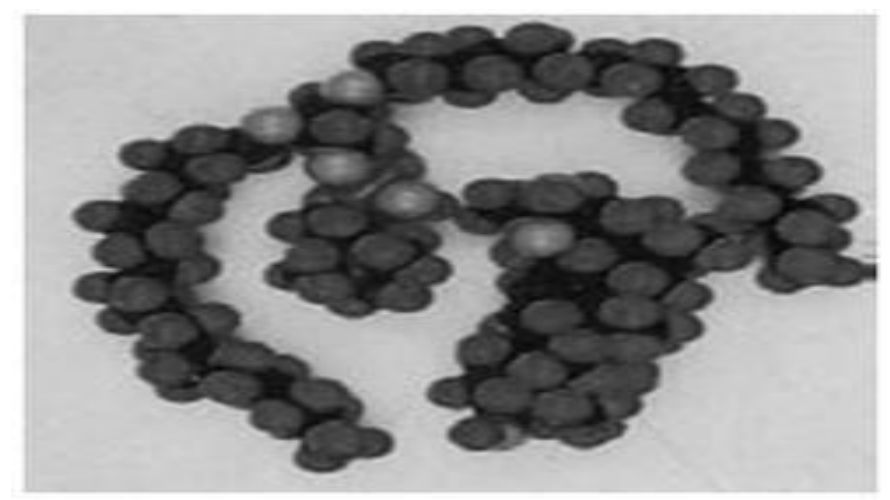

Figure 2 Molecular arrangement showing hydrophobic tail surrounding the hydrophilic choline part

Small dose is required, as absorption is increased manifolds.

Phytosomes possess better drug entrapment efficiency.

Phosphatidylcholine is not merely a carrier; it is also having hepatoprotective activity and nutritional value.

Due to formation of chemical bonds, phytosomes show better stability profile.

Phytosomes can be used for systemic targeting of herbal drugs, as phytosome can easily transit from hydrophilic environment into the lipid friendly environment of the enterocyte cell membrane and from there to into the cell.

Cosmetic and other topical use of phytoconstituents can be done by phytosome formulations

\section{Properties of phytosomes}

\subsection{Physico-chemical properties}

As previously discussed, phytosomes are prepared by reaction of stoichiometric amount of phospholipid with the standardized plant extract as substrate. The spectroscopic data reveals that the phospholipid- substrate interaction is due to the formation of hydrogen bond between the polar head (i.e., phosphate and ammonium group) and the polar functionalities of the substrate.

The size of phytosome varies from $50 \mathrm{~nm}$ to a few $100 \mu \mathrm{m}$.

Phytosomes when treated with water, they assume a micellar shape resembling liposome and Photon Correlation Spectroscopy (PCS) reveals these liposomal structures acquired by Phytosomes.

From the 1HNMR and 13CNMR data, it can be deduced that the fatty chain gives unchanged signals both in free phospholipid and in the complex, which indicates that long aliphatic chains are wrapped around the active principle, producing lipophilic envelope.

Regarding the solubility of phytosomes, the complexes are often freely soluble in aprotic solvents, moderately soluble in fats, insoluble in water and relatively unstable in alcohol. But the phytosomes of certain lipophilic phytoconstituents like curcumin has shown increased water solubility upon complexation with phospholipids which has been discussed later in this paper [7] [8].

\subsection{Biological properties}

Phytosomes are novel complexes which are better absorbed and utilized, hence they produce more bioavailability and better result than the conventional herbal extract or non-complexed extracts, which has been demonstrated by pharmacokinetic studies or by pharmacodynamic tests in experimental animals and in human subjects.

Phytosomes express their behavior in physical or biological system because of their physical size, membrane permeability, percentage entrapment, chemical composition, quantity and purity of the materials used. 
The phytotomies should not be confused with liposomes where hydrophilic drug molecules are entrapped within a cavity or spaces between the membranes.

The liposomes may involve several hundred phospholipid molecules for this entrapment and are usually now being used for cosmetic purposes.

Instead, the phytosomes involves interaction of 1- 4 phospholipid molecules with the phytoconstituents which are chemically anchored to each other. Several researches have shown the phytosomes to be a better alternative for liposomes in terms of membrane permeability and stability [8].

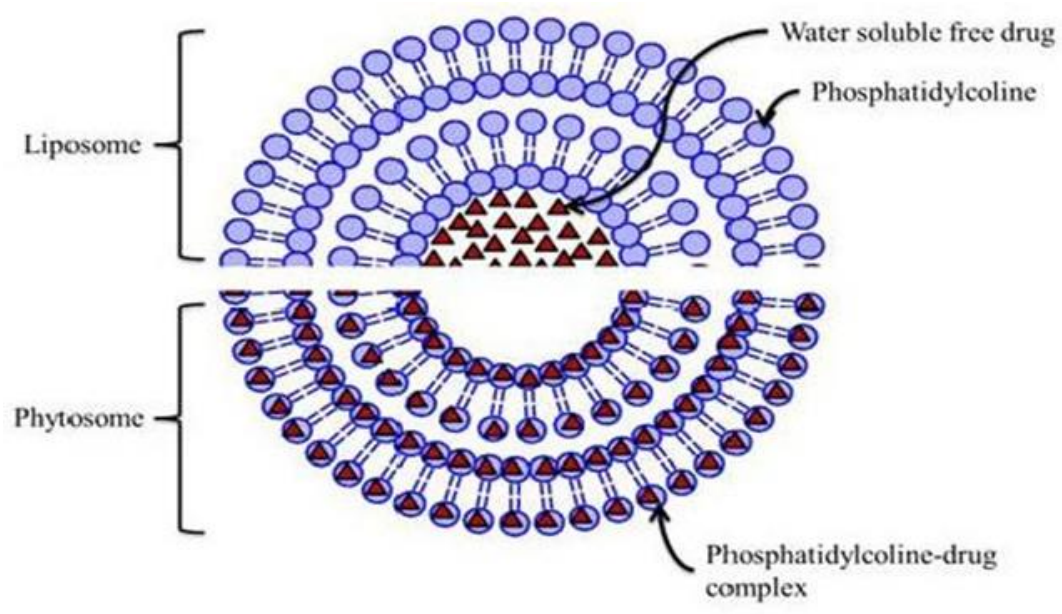

Figures 3 Illustration on comparative account of phytosomes and liposomes.

\subsection{Comparison between phytosome and liposom}

There are number of research which has been carried out on phytosomes which state that phytosomes have good bioavailability, absorption, and excellent therapeutic efficacy over liposome. Comparison between phytosomes and liposomes is represented in Table 1 along with their structure in Figure. 4 [9].

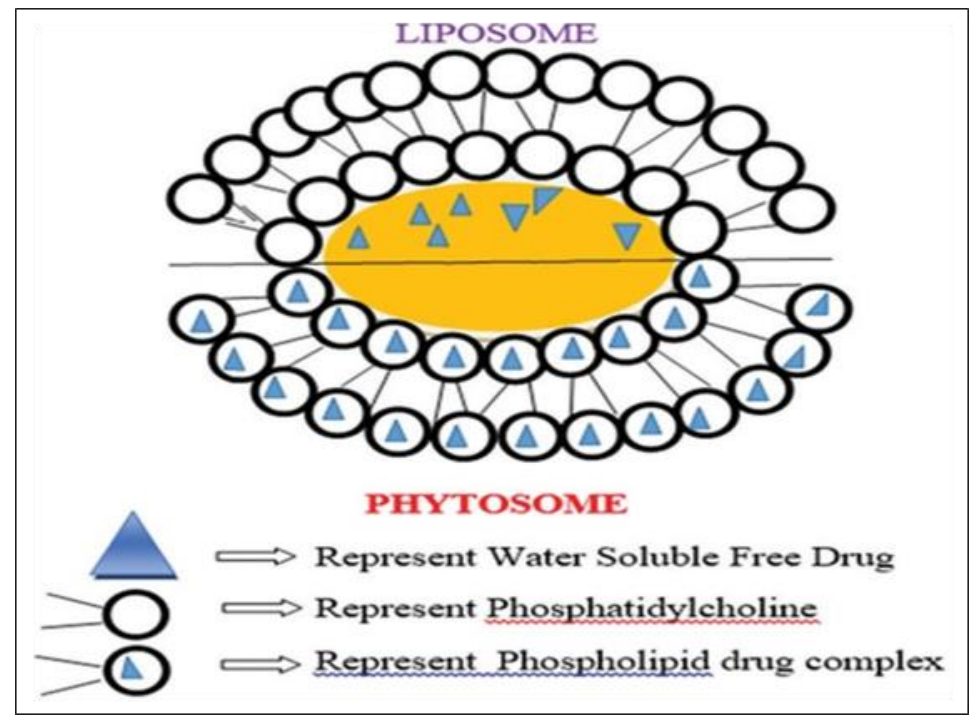

Figure 4 Comparison between liposome and phytosome 
Table 1 Comparison between phytosomes and liposomes

\begin{tabular}{|l|l|l|l|l|}
\hline $\begin{array}{l}\text { Sr. } \\
\text { No }\end{array}$ & Properties & Phytosome & Liposome & $\begin{array}{l}\text { Refer } \\
\text { ences }\end{array}$ \\
\hline 1. & Bonding & $\begin{array}{l}\text { Associated with few molecule } \\
\text { (mainly with Phospholipid } \\
\text { and polyphenol extract })\end{array}$ & $\begin{array}{l}\text { Number of molecules and even } \\
\text { they are not connected well }\end{array}$ & {$[7]$} \\
\hline 2. & Oral drug delivery & Best for oral delivery & $\begin{array}{l}\text { connected well } \\
\text { poor oral } \\
\text { bioavailability. }\end{array}$ & {$[8]$} \\
\hline 3. & Phospholipid ratio & $\begin{array}{l}\text { Preferably 1:1, 1:2 ratio is } \\
\text { preferred for its preparation. }\end{array}$ & $\begin{array}{l}\text { Lipid ration is increased up to 10 } \\
\text { times than the chief active } \\
\text { constituents }\end{array}$ & {$[9]$} \\
\hline
\end{tabular}

Table 2 Commercially available phytosomal product

\begin{tabular}{|c|c|c|c|c|c|}
\hline $\begin{array}{l}\text { Sr. } \\
\text { No. }\end{array}$ & Trade name & Chief constituents & Source & Dose & Use \\
\hline 1 & $\begin{array}{l}\text { Centella } \\
\text { phytosomes }\end{array}$ & Triterpine & Centella asiatica & - & Cicatrizing, trophodermic \\
\hline 2 & $\begin{array}{l}\text { Ginselect } \\
\text { phytosomes }\end{array}$ & Ginsenosides & Gingko biloba & $120 \mathrm{mg}$ & Adaptogenic \\
\hline 3 & $\begin{array}{l}\text { Greenselect } \\
\text { phytosomes }\end{array}$ & Polyphenols & Camellia sinensis & - & $\begin{array}{l}\text { Free radical scavenging } \\
\text { activity }\end{array}$ \\
\hline 4 & Leucoselect & Polyphenols & Vitis vinifera & $300 \mathrm{mg}$ & Antioxidant \\
\hline 5 & Meriva & Curcuminoids & Curcuma longa & $\begin{array}{l}200-300 \\
\mathrm{mg}\end{array}$ & Anti-inflammatory \\
\hline 6 & Silymarin & Silymarin & Silybum marianum & - & Antihepatotoxic \\
\hline 7 & $\begin{array}{ll}\text { Oleaselect } & \text { TM } \\
\text { phytosome } & \end{array}$ & $\begin{array}{l}\text { Polyphenols of olive } \\
\text { oil }\end{array}$ & Olea europaea & - & $\begin{array}{l}\text { Anti-inflammatory, } \\
\text { antioxidant }\end{array}$ \\
\hline 8 & $\begin{array}{l}\text { Crataegus } \\
\text { phytosomes }\end{array}$ & $\begin{array}{l}\text { Vitexin-2'-0- } \\
\text { rhamonoside }\end{array}$ & $\begin{array}{l}\text { Crataegus } \\
\text { Mexicana }\end{array}$ & - & Antioxidant \\
\hline 9 & Visnadine & Visnadine & Ammi visnaga & - & Circulation improver \\
\hline 10 & Bilberry & Triterpine & $\begin{array}{l}\text { Vaccinium } \\
\text { myritillus }\end{array}$ & - & Potent antioxidant \\
\hline 11 & $\begin{array}{l}\text { Ruscogenin } \\
\text { phytosomes }\end{array}$ & Steroid saponin & Ruscus aculeatus & - & Anti-inflammatory \\
\hline 12 & PA2 phytosomes & Proanthocynidin & Horse chestnut bark & - & $\begin{array}{l}\text { Antiwrinkles, } \\
\text { protectant }\end{array}$ \\
\hline 13 & $\begin{array}{l}\text { Zanthalene } \\
\text { phytosomes }\end{array}$ & Zanthalene & $\begin{array}{l}\text { Zanthoxylum } \\
\text { bungeanum }\end{array}$ & - & Soothing, anti-itching \\
\hline 14 & $\begin{array}{l}\text { Lymphaselect } \\
\text { phytosomes }\end{array}$ & Triterpenes & Melilotus officinalis & - & Indicated in insomnia \\
\hline 15 & $\begin{array}{l}\text { Sabalselect } \\
\text { phytosome }\end{array}$ & Fatty acid, sterols & Serenoa repens & - & $\begin{array}{ll}\text { Beningn } & \text { prostate } \\
\text { hyperplasia } & \end{array}$ \\
\hline 16 & $\begin{array}{l}\text { Sericoside } \\
\text { phytosome }\end{array}$ & Sericosides & Terminalia sericea & - & Skin improver \\
\hline 17 & $\begin{array}{l}\text { Echinacea } \\
\text { phytosome }\end{array}$ & Echinacosides & $\begin{array}{l}\text { Echinacea } \\
\text { angustifolia }\end{array}$ & - & $\begin{array}{l}\text { Immunomodulators, } \\
\text { nutraceuticals }\end{array}$ \\
\hline 18 & Rexatrol & Resveratrol & $\begin{array}{l}\text { Polygonum } \\
\text { cuspidatum }\end{array}$ & - & Antioxidant, antiaging \\
\hline
\end{tabular}




\subsection{Preparation of phytosome}

Phytosomes are generally prepared by adding accurate amount of phospholipid, i.e., Soya lecithin with herbal extracts in an aprotic solvent. Soya lecithin contains main constituent, i.e., Phosphatidylcholine which is having a dual function. Phosphatidyl part is lipophilic in nature and choline part is hydrophilic in nature. The choline part attached with hydrophilic chief active constituents, whereas phosphatidyl part lipid soluble compound attached with choline bound complex. It results in the formation of lipid complex with better stability and bioavailability.

In another way Phytosomes are prepared by reacting a synthetic or natural phospholipid with the standardized plant extract in a ratio ranging from $0.5-2.0$. But usually $1: 1$ ratio is preferable. The reaction is carried out alone or in the natural mixture in aprotic solvent, such as, dioxane, methylene chloride, acetone; from which the novel complex can be isolated by precipitation with a non-solvent, usually an aliphatic hydrocarbon or by lyophilization or by spay drying. The solubilization or complex formation is sometimes carried out by refluxing the stoichiometric ratio mixture for a specified period in the aprotic solvent.

Phytosome vesicles were made by thin layer rotary evaporator vacuum method. The phytosomal complex was mixed in anhydrous ethanol in $250 \mathrm{ml}$ round bottom flask. The flask was attached to a rotary evaporator. The solvent will evaporate at a temperature about $60^{\circ} \mathrm{C}$ forming thin layer film around the flask. The film is hydrated by phosphate buffer having $\mathrm{pH}$ 7.4 , and the lipid layer will peel off in phosphate buffer forming vesicle suspension. The phytosomal suspension was subjected to probe sonication with $60 \%$ amplitude. Phytosomal suspension will be stored in the refrigerator for 24 hrs., before characterization .

Phytosomes can be prepared by reflux method. Polyphenolic extract and phospholipid were placed in $100 \mathrm{~mL}$ round bottom flask and refluxed in DCM for $1 \mathrm{hr}$. not exceeding $40^{\circ} \mathrm{C}$. The clear solution was evaporated and add $15 \mathrm{~mL}$ of n-hexane until a precipitate was obtained. The precipitate was taken and placed in a desiccator . [10]

Accurately, weight the quantity of phospholipid and cholesterol in round bottom flask and dissolve it in $10 \mathrm{~mL}$ of chloroform followed by sonication for 10 minutes using bath sonicator. Organic solvent removal can be done by subjecting it under reduced pressure in a rotary evaporator $\left(40^{\circ} \mathrm{C}\right)$. After complete removal of the solvent thin layer is formed which is hydrated with polyphenolic extract of the drug in a rotary evaporator. Phospholipids mixture was sonicated in an ice bath for heat dissipation. Prepared phytosome were stored in an amber colored bottle.The diagrammatic representation of procedure is shown in Figure [11] [12].

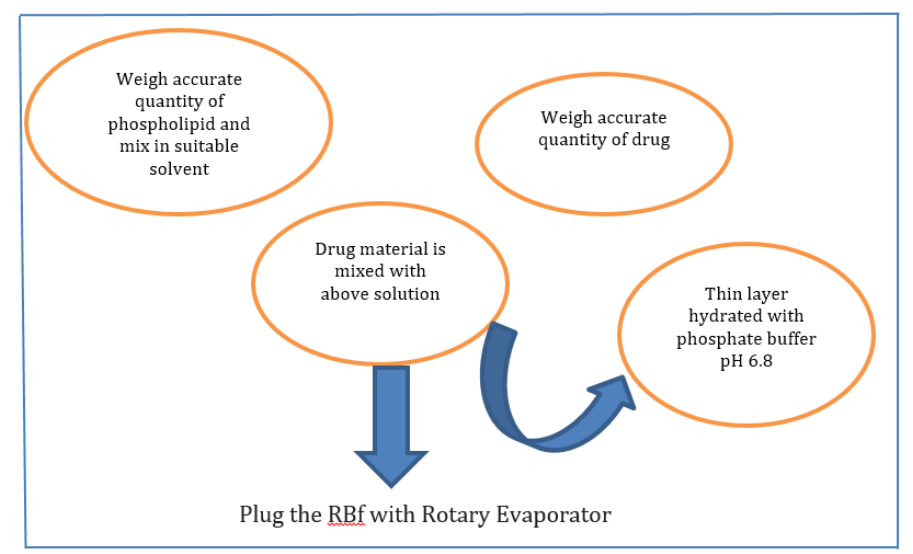

Figure 5 General Preparation of Phytosome

\section{Mechanism of phytosome technology}

The lower absorption and bioavailability of polyphenolic constituents mainly due to two factors.

These chief constituents are number of ringed molecule and are not too much small that it will absorbed by diffusion process.

Second factor is that flavonoid molecule or chief constituents of polyphenols have poor solubility with lipids. 
These are the limitations that inhibit their absorption through biological membrane. Phytosome technology is mainly result with complexation of polyphenols with phospholipid in 1:1 ratio or 1:2 results in the formation of phytosomal complex with lipid covering around the constituents [13].

\subsubsection{Differential scanning calorimetry}

Drug polyphenolic extract, phosphatidylcholine, a physical mixture of drug extract and Phosphatidylcholine, and drugphospholipid complex placed in an aluminum cell and heated to a temperature of $50-250^{\circ} \mathrm{C} / \mathrm{minutes}$ from 0 to $400^{\circ} \mathrm{C}$ in the atmosphere of nitrogen.

\subsubsection{Scanning electron microscopy (SEM)}

SEM was used to determine the size of the particle and its appearance. Dry sample was placed on electron microscope brass stub coated with gold in an ion sputter. Random scanning of the complex at 100.

\subsubsection{Transition electron microscopy (TEM)}

TEM was used to characterize the size of phytosomal vesicles with 1000 magnification

\subsubsection{Drug entrapment and loading capacity}

Drug phytosomes complex was centrifuged at $10000 \mathrm{rpm}$ for 90 minutes at $4^{\circ} \mathrm{C}$ to separate phytosome from the untrapped drug. The concentration of free drug can be measured by doing ultraviolet spectroscopy. The percentage drug entrapment can be calculated as given formula:

Weight of total drug - Entrapment efficiency $\%=\frac{\text { weight of free drug }}{\text { wight of total drug }} \times 100$

\subsubsection{Fourier transform infrared spectroscopy (FTIR) analysis}

FTIR analysis done for checking the structure as well as chemical stability of drug, phospholipid. The phytosomal drug will be crushed with potassium bromide to obtain pellets at $600 \mathrm{~kg} / \mathrm{cm} 2$ pressure. Scanning will be done between the ranges of $4000-400 \mathrm{~cm}^{-1}$.

\subsubsection{Size analysis and zeta potential}

Malvern Zetasizer is used to check the particle size and zeta size of phytosomal complex. Argon laser is used for this particle size and zeta sizer characterization.

\subsubsection{In vitro and in vivo evaluations}

In vitro and in vivo evaluation depend on the properties of the drug, their chief phytoconstituents bounded by phospholipid layer and on the bases of that particular animal model is selected for its evaluation [14] [16].

\section{Applications}

Over the past century, phytochemical and phytopharma- cological sciences established the compositions, biological activities and health promoting benefits of numerous plant products.

Most of the biologically active constituents of plants are polar or water soluble molecules. However, water soluble phytoconstituents (like flavonoids, tannins, terpenoids, etc.) are poorly absorbed either due to their large molecular size which cannot absorb by passive diffusion, or due to their poor lipid solubility; severely limiting their ability to pass across the lipid-rich biological membranes, resulting poor bioavail-ability.

It has often been observed that the isolation and purification of the constituents of an extract may lead to a partial or total loss of specific bio-activity for the purified constituent - the natural constituent synergy becomes lost. Very often the chemical complexity of the crude or partially purified extract seems to be essential for the bioavailability of the active constituents. Extracts when taken orally some constituents may be destroyed in the gastric 
environment. As standardized extracts are established, poor bioavailability often limits their clinical utility due to above said reasons [16][17].

It has been observed that complexation with certain other clinically useful nutrients substantially improves the bioavailability of such extracts and their individual constituents.

The nutrients so helpful for enhancing the absorption are the phospholipids.

Phytosome is a patented technology devel- oped by a leading manufacturer of drugs and nutraceuticals, to incorporate standardized plant extracts or water soluble phytoconstituents into phospholipids to produce lipid com- partible molecular complexes, called as phytosomes and so vastly improve their absorption and bioavailability.

In liposomes no chemical bond is formed; the phosphatidylcholine molecules surround the water soluble substance.

There may be hundreds or even thousands of phosphatidylcholine molecules surrounding the water soluble compound.

In contrast, with the phytosome process the phosphatidylcholine and the plant components actually form a $1: 1$ or a 2:1 molecular complex depending on the substance(s) complexed, involving chemical bonds.

Phospho- lipids are complex molecules that are used in all known life forms to make cell membranes.

In humans and other higher animals, the phospholipids are also employed as natural digestive aids and as carriers for both fat-miscible and water miscible nutrients.

They are miscible both in water and in lipid environments, and are well absorbed orally. Phytosomes are more bioavailable as compared to conventional herbal extracts owing to their enhanced capacity to cross the lipoidal bio membrane and finally reaching the systemic circulation [18].

\section{Compliance with ethical standards}

\section{Acknowledgments}

With reverence, I sincerely accentuate my everlasting heartfelt gratitude and indebtness to my guide Archana D. Kajale, Madhuri A. Channawar and Shilpa. R. Gawande. I owe special thanks to my Friends for their valuable suggesions and help.

\section{Disclosure of conflict of interest}

We declare that we have no conflict of interest.

\section{References}

[1] Kumar A., Kumar B., Singh S.K., Kaur B., Singh S., "A review on phytosomes: Novel approach for herbal phytochemicals" Asian Journal of Pharmaceutical and Clinical Research 2007, 10(10), 42.

[2] Semalty A., Semalty M., Rawat M.S., Franceschi F., "Supramolecular phospholipids-polyphenolics interactions, the phytosome strategy to improve the bioavailability of phytochemicals" Fitoterapia 2010, 81(5), 306-14.

[3] Gandhi A., Dutta A., Pal A., Bakshi P., "Recent trend of phytosomes for delivering herbal extract with improved bioavailability" J Pharmakon Phytochem 2012, 1(4), 6.

[4] Kalita B., Das K.M., Sharma K.A., "Novel phytosome formulation making herbal extract more effective” J Pharm Technol 2013, 6 (11), 1295.

[5] Jadhav I.A., Wadhave A.A., Arsul V.A., Sawarkar H.S., "Phytosome a novel approach in herbal drug" Int J Pharm Anal 2014, 2(5), 478.

[6] Mukherjee P.K., Wahile A., "Integrated Approaches towards drug development from Ayurveda and other Indian System of Medicine" Journal of Ethnopharmacology, 2006, 103, 25-35. 
[7] Franceschi F., Giori A., "(Indena S.p.A.). Phospholipid complexes of olive fruits or leaves extract having improved bioavailability" Patent app. W02007118631, 2007.

[8] Manach C., Scalbert A., Morand C., "Polyphenols, food sources and bioavailability" The American Journal of clinical Nutrition, 2004, 79, 727-47.

[9] Jain N., Gupta P.B., Thakur N., Jain R., Banweer J., "Phytosome a novel drug delivery system for herbal medicine" Int J Pharm Sci Drug Res 2010, 2(4), 224.

[10] Kareparamban A.J., Nikam H.P., Jadhav P.A., Kadam J.V., “Phytosome a novel revolution in herbal drugs” Int J Res Pharm Chem 2012, 2(2), 300.

[11] Dhase S.A., Saboo S.S., "Preparation and evaluation of phytosome containing methanolic extract of leaves of Aegle marmelos (Bael)" Int J Pharm Technol Res 2015, 8(6), 232-3.

[12] Amin T., Bhat S., "A review on phytosome technology as a novel approach to improve the bioavailability of nutraceuticals" Int J Online Adv Res Technol 2012, 1, 1-15.

[13] Kidd P.M., "Bioavailability and activity of phytosome complexes from botanical polyphenols, The silymarin, curcumin, green tea, and grape seed extracts” Altern Med Rev 2009, 14(3), 226-46.

[14] Bombardelli E., Mustich G., "Bilobalide Phospholipid Complex their Uses and Formulation Containing them" U.S Patent No. EPO275005, 1991.

[15] Ghanbarzadeh B., Babazadeh A., Hamishekhar H., "Nano-phytosome as a potential food-grade delivery system" J Food Sci 2016, 15, 126-35.

[16] Middleton E., Kandaswami C., "The impact of plant flavonoids on mammalian biology: implications for immunity, inflammation, and cancer" In Harborne JB, editor, The Flavonoids, Advances in Research Since 1986. 1st Ed, 1994, London, Chapman and Hall, 1994, 619-652.

[17] Murray D.Phytosomes-Increase the Absorption of Herbal Extract [online].2008[cited 2008 Sep 28].Available from: URL: www.doctormurray.com/article/silibin.htm.

[18] Pandey S., Patel K., "Phytosomes, Technical Revolution in Phytomedicine" International Journal of Pharm Tech Research, 2010, 2 (1), 627-631.

[19] Schandalik R.E., "Perucca, Pharmacokinetics of silybin following oral administration of silipide in patients with extrahepatic biliary obstruction” Drugs under Experimental \& Clinical Research, 1994, 20, 37-42.

[20] Mascarella S. Therapeutic and antilipoperoxidant effects of silybin-phosphatidylcholine complex in chronic liver disease. Preliminary results, Current Therapeutic Research, 1993, 53 (1), 98-102.

[21] Grange L., Wang M., Watkins R., Ortiz D., Sanchez M.E., Konst J., Lee C., Reyes E., "Protective effects of the flavonoids mixture, silymarin, on fetal rat brain and liver" Journal of Ethnopharmacology, 1999, 65, 53-61.

[22] Busby A., Grange L., Edwards J., Kings J., "The use of a silymarin/phospholipids compound as a fetoprotectant from ethanol-induced behavioral deficits" Journal of Herbal Pharmacotherapy, 2002, 2 (1), 39-47.

[23] Jiang Y.N., Yu Z.P., Yan Z.M., Chen J.M., "Studies on preparation of herbal epimedin flavonoid phytosomes and their pharmaceutics" Zhongguo Zhong Yao Za Zhi, 2001, 26 (2), 105-8. 